\title{
Numerical study and design of aluminium alloy channel section columns with welds
}

DOI:

10.1016/j.tws.2019.03.015

\section{Document Version}

Accepted author manuscript

Link to publication record in Manchester Research Explorer

\section{Citation for published version (APA):}

Zhu, J., Li, Z., Su, M., \& Young, B. (2019). Numerical study and design of aluminium alloy channel section columns with welds. Thin-Walled Structures, 139, 139-150. https://doi.org/10.1016/j.tws.2019.03.015

\section{Published in:}

Thin-Walled Structures

\section{Citing this paper}

Please note that where the full-text provided on Manchester Research Explorer is the Author Accepted Manuscript or Proof version this may differ from the final Published version. If citing, it is advised that you check and use the publisher's definitive version.

\section{General rights}

Copyright and moral rights for the publications made accessible in the Research Explorer are retained by the authors and/or other copyright owners and it is a condition of accessing publications that users recognise and abide by the legal requirements associated with these rights.

\section{Takedown policy}

If you believe that this document breaches copyright please refer to the University of Manchester's Takedown Procedures [http://man.ac.uk/04Y6Bo] or contact uml.scholarlycommunications@manchester.ac.uk providing relevant details, so we can investigate your claim.

\section{OPEN ACCESS}


Ji-Hua Zhu, Zi-qi Li, Mei-Ni Su and Ben Young, (2019) "Numerical study and design of aluminium alloy channel section columns with welds", Thin-Walled Structures, 139: 139-150.

\title{
Numerical study and design of aluminium alloy channel section columns with welds
}

\author{
Ji-Hua Zhu ${ }^{1}$, Zi-qi $\mathrm{Li}^{1}$, Mei-Ni $\mathrm{Su}^{2} *$ and Ben Young ${ }^{3}$ \\ ${ }^{1}$ Department of Civil Engineering, Shenzhen University, Shenzhen, China \\ 2 * School of Mechanical, Aerospace and Civil Engineering, University of Manchester, Manchester, UK, \\ email: meini.su@manchester.ac.uk \\ ${ }^{3}$ Department of Civil and Environmental Engineering, The Hong Kong Polytechnic University, Hong \\ Kong, China (Formerly, Department of Civil Engineering, The University of Hong Kong, Pokfulam \\ Road, Hong Kong, China)
}

\begin{abstract}
This paper presents a numerical investigation on aluminium alloy welded columns of channel section. Non-linear finite element models were firstly developed and validated against non-welded column test results. The materials considered in this study were aluminium alloys 6063-T5 and 6061-T6. The validated finite element models were used for parametric studies to generate numerical results for columns containing welds. In the finite element models, both ends of the columns were transversely welded to aluminium alloy end plates. Finite element models of welded columns were developed by dividing the column into two part: non-welded region and heat-affected zones. Material properties of non-welded aluminium alloys and heat-affected zone were adopted in the models. A total of 100 numerical results were newly generated from the parametric study. The numerical results were compared with design strengths predicted by the existing American, Australian/New Zealand, European and Chinese standards. The column strengths were also compared with the design strengths by the direct strength method (DSM) and the continuous strength method (CSM). Modified DSM and CSM approaches with the consideration of heat-affected zone softening effects were proposed in this study. Both modified DSM and CSM approaches were found to yield more accurate and consistent predictions for aluminium alloy welded columns. In addition, reliability analyses were performed to evaluate the reliability level of all the existing and newly proposed design rules for channel section columns containing transverse welds.
\end{abstract}

\section{Keywords:}

Aluminium alloy; Channel section; Column; Continuous strength method; Direct strength method; Finite element analysis; Transverse welds. 


\section{Introduction}

Owing to the high strength-to-weight ratio, great corrosion resistance and aesthetic appearance, aluminium alloy members are being widely used in engineering applications [1]. Aluminium alloy members such as columns and beams could be easily connected to each other by welding [5]. When heat-treated aluminium alloys are welded, the heat generated from the welding process significantly change the microstructure and properties in a localized region, such region is known as the heat affected zone (HAZ). At microstructural level, the HAZ can be divided into over-aging zone and quenching zone. The dissolution and growth of precipitate phase in over-aging zone leads to the increase of precipitate phase spacing and the decrease of precipitate particles, resulted in the serious loss of strength and hardness of base metal [3]. Due to the welding process in aluminium alloys, local strength loss due to the development of HAZ affects the structural behaviour of aluminium components [4]. At the material level, tensile coupon tests can be carried out on both welded and non-welded aluminium alloys. Based on the experimental results [5], it can be found that in the case of the 6000 series aluminium alloys, the transverse welds might reduce their $0.2 \%$ proof stress up to $68 \%$. At the member level, the effects of welding on members depend on the position, direction and number of welds. It is found that the circular hollow section (CHS) columns containing welds can only reach 54\% - 76\% of the strength of non-welded columns [5]. Hence, it is important to understand the behaviour of aluminium alloy members containing welds and provide reliable design approaches for these members for practical design purpose, since welding is one of the commonly used connection methods for aluminium alloy structures.

Because of the increasing popularity of aluminium alloy structures, there have been continuous investigations on their behaviour and design, especially compression members. The majority are focused on non-welded members, covering different cross-sections and aluminium alloys. Su and Young [6] carried out a series of stub column tests on box sections with and without internal cross stiffeners. Liu and Zhang [7] studied buckling behaviours of aluminium alloy columns of complicated sections. Adeoti et al. [8] proposed a column curve for H-section and rectangular hollow section columns of aluminium alloy 6082-T6. Wang and Fan [9] investigated the stability of aluminium alloy column based on a series of compression tests on aluminium alloy 6082 circular tubes. However, the relevant data on welded columns are scarce. Zhu and Young [5, 10, 11] experimentally and numerically investigated the effects of transverse welds on aluminium alloy columns of square, rectangular and circular hollow sections (SHS, RHS, CHS). Ashraf and Young [12] proposed design equations to predict the resistance of aluminium alloy stub and long columns (SHS and RHS) with transverse welds. Wang et al. [13] and De Matteis et al. [14] investigated the effects of welds on aluminium alloy member joints by numerical study. However, there is no experimental or numerical data on channel section columns containing welds. The softening effects in the heat affected zone on open section columns need careful investigations with support of more sufficient data. Therefore, to address the lack of test data and to investigate their structural response, this study performed numerical investigation on aluminium alloy channel columns with transverse welds. 
Currently, the compression capacity of aluminium alloy columns can be predicted by international design standards, such as the American Aluminium Design Manual (AA) [15], the Australia and New Zealand Standards (AS/NZS) [16], Eurocode 9 (EC9) [17] and the Chinese Code for Design of Aluminium Structures (CN) [18]. In the AA and AS/NAS, the influence of welding length is considered for the design of columns containing transverse welds at both ends. When the length of the end welds is greater than $5 \%$ of the column length, the column is calculated according to the welding material properties. In EC9 and CN standards, the weakening effects of welds are considered by adopting a heat-affected zone (HAZ) softening factor. Besides, there are two widely used design methods for aluminium alloy members - the direct strength method (DSM) and the continuous strength method (CSM). The DSM approach was initially developed based on cold-formed steel structures and is codified in the North American Specification (NAS) [19]. Zhu and Young [11] modified the DSM for aluminium alloy columns of square, rectangular and circular hollow sections. As for the CSM approach for aluminium alloy structures, Su et al. [20] proposed design methods for non-welded columns and Ashraf and Young [12] developed the design rules for welded columns.

The aims of this study are to generate numerical results for channel section columns containing welds and to propose accurate design rules for these members. This research project used finite element (FE) software ABAQUS [21] to develop numerical models for channel section columns and validated by experimental results [22]. The validated models incorporated welding material properties obtained from tensile tests. The non-welded material properties were used in the main part of the column, while the welded material properties were used in the heat affected zone at both ends. Parametric study was conducted using the validated models to generate a total of 100 channel section columns containing transverse welds at both ends. The key parameters considered in the parametric study include two types of alloys (6061-T6 and 6063-T5), five column lengths (500, 1200, 2000, 2700 and $3500 \mathrm{~mm})$ and five width-to-thickness ratios (20, 40, 60, 80 and 100). The numerical results were used to assess the design rules in the American, Australian/New Zealand, European, and Chinese standards as well as the DSM and CSM approaches. Both DSM and CSM approaches were modified to consider the softening effects in the heat-affected zone. The suitability of different design methods is assessed herein. In addition, reliability analysis was also conducted to assess all the existing and modified design approaches against the new data pool.

\section{Summary of test results}

\subsection{Collected column test results}

A series of compression test results reported by Zhu et al. [22] is collected and used in this study to validate the FE models. The test programme included 14 plain channel section columns and 14 lipped channel section columns without welds. The test specimens were fabricated by extrusion using 6063-T5 and 6061-T6 heat-treated aluminium alloys. Each specimen was cut to a specified length ranging from 300 to $3000 \mathrm{~mm}$. A rigid bearing plate was bolted to the end supports to achieve 
the fix-ended condition. The details of test set-up and test results can be found in [22].

\subsection{Tensile coupon tests on welded materials}

Non-welded and welded material properties were measured on plain and lipped channel section columns. The non-welded longitudinal tensile coupons tests were detailed in Zhu and Young [2]. In this paper, the welded longitudinal tensile coupons were tested to determine the welded material properties, as shown in Fig. 1. The welded tensile coupons of $25 \mathrm{~mm}$ gauge length were taken from the centre of the faces of the channel section between two parallel welds as suggested by Sharp [23]. The distance between the centre lines of two longitudinal welds was approximately $32 \mathrm{~mm}$. It ensures the coupons are fully heat-affected based on previous research that the HAZ is limited to approximately 3 in to either side of the weld centreline. The measured material properties of each specimen were determined by longitudinal tensile coupon tests and Webster hardness measurements. Coupon tests conformed to the AS 1391-2007 [24] and the ASTM E8M-97standard [24]. The measured material properties are shown in Table 1.

\section{Finite element modelling}

The finite element (FE) programme ABAQUS [21] was used for numerical simulation in this study. The developed FE models were validated against test results of non-welded columns. Afterwards, the models were further developed to simulate the loading behaviour of aluminium alloy welded columns. A parametric study was performed to examine the effects of key geometry parameters on the compressive strength of aluminium alloy columns with plain and lipped channel sections. The studied parameters included effective length, width-to-thickness ratio and slenderness ratio. The numerical results from the parametric study in this section are used to evaluate the design methods.

\subsection{Model development and validation}

An accurate and reliable non-linear FE model for aluminium non-welded columns of plain and lipped channel sections has been developed. The simulation consisted of two steps. In the first step, an elastic buckling analysis, which is known as linear perturbation analysis, was performed on the perfect geometry of a column to obtain its eigenvalue buckling modes. In the next step, a non-liner analysis using modified Riks to obtain the ultimate load and failure modes of column. The FE model employed the S4R general-purpose shell elements with the experimentally measured material properties. The element sizes in the FE models of plain and lipped channel sections were $10 \times 10 \mathrm{~mm}$ (length by width) and $5 \times 5 \mathrm{~mm}$, respectively. The measured material properties [22] of the non-welded columns were used in the FE modelling. Stress-strain curves of the normal and high strength aluminium alloys are shown in Fig. 2. Both initial local and overall geometric imperfections were included in the model. The local and overall buckling modes were obtained by Eigenvalue analysis of the columns by 
changing the width-to-thickness ratio [26]. The magnitudes of the imperfection were determined based on the measurement. The fixed-ended boundary condition was simulated by restraining all the degrees of freedom of the nodes at both ends, except for the translational degree of freedom in the axial direction at one end of the column.

The developed FE model was validated against the experimental results [22], as shown in Tables 2-3. Typical load-deformation curves obtained from experiments and FE models are compared in Fig. 3. It is shown that the ultimate loads obtained from the FE $\left(P_{F E}\right)$ are generally in good agreement with the experimental results $\left(P_{E x p}\right)$. Meanwhile, the failure modes predicted by the FE are mostly identical to those observed in the tests. Please note that the failure modes presented in [27] contain typo and the corrected failure modes are presented in Tables 2-3 herein.

\subsection{Parametric study}

The FE model closely predicted the experimental ultimate loads and failure modes of the aluminium channel section columns [27]. Hence, the validated model was used for an extensive parametric study. The parametric study includes 100 simulated columns. The dimensions of the column cross-sections are shown in Table 4, where $H, B, B_{l}, t$ are the cross-section depth, cross-section width, stiffener length, cross-section thickness, respectively. Each cross-section has five specimens with column lengths $(L)$ of 500,1200, 2000, 2700 and $3500 \mathrm{~mm}$. The specimens were labelled such that the type of section, the type of aluminium alloy, welding condition and column length could be identified, as shown in Table 4. For example, the label "P-T5-M1-W-L500" defines the following specimen:

- The first letter indicates the type of section of the specimen, where "P" refers to the plain channel section, and " $L$ " refers to the lipped channel section.

- The second part of the label indicates the type of material of the specimen, where "T5" refers to the aluminium alloy 6063-T5, and "T6" refers to the aluminium alloy 6061-T6.

- The third part of label indicates the cross-section dimensions of specimen. The cross-section dimensions of all series are shown in Table 4.

- The following part of the label "W" indicates the welding condition of the specimen.

- The last part of the label "L500" indicates the nominal length of the column (500 mm).

The welded columns were modelled by dividing the columns into three parts, the HAZ regions at both ends of the columns, and the non-welded region of the main body of the columns, as shown in Fig. 4. The extension of HAZ was determined as $25 \mathrm{~mm}$ in length and the mesh dimension of the HAZ was $5 \times 5 \mathrm{~mm}$ was used. The non-welded material properties used in the parametric study are identical to the material properties of specimens in the experimental programme [21]. The welded material properties are detailed in Table 1 herein. The local imperfection magnitude was $10 \%$ of the section thickness, and the overall imperfection magnitude was 1/2000 of the column length. The mesh size for plain channel section columns was $10 \mathrm{~mm} \diamond 10 \mathrm{~mm}$ and that for lipped channel section columns 5 $\mathrm{mm} \diamond 5 \mathrm{~mm}$, respectively. The failure modes obtained from the parametric study included: local buckling, flexural buckling and distortional buckling, as shown in Fig. 5. By observation, it was found that short columns failed by local bucking at the HAZ, while the failure modes of medium and long columns were similar to non-welded columns. The column strengths $\left(P_{F E}\right)$ obtained from the 
parametric study are shown in Tables 5-8.

\section{Design approaches}

\subsection{Existing design rules for aluminium alloy structures}

The American Aluminium Design Manual (AA) [15], the Australia and New Zealand Standards (AS/NZS) [16], Eurocode 9 (EC9) [17] and the Chinese Code for Design of Aluminium Structures (CN) [18] provide design rules for aluminium columns with transverse welds. In the prediction, all partial safety factors are set to be the unity.

The design rules in the AA standard for the design strengths of aluminium columns with transverse weld are described in Chapter E [15], which depends on the length of welds. When the length of transvers welds is more than $5 \%$ of the column length, the design strengths is calculated using the welded mechanical properties and the buckling constants from Table B 4.1 and Table B 4.3 of Part I of the AA [15]. When the length of transvers welds is less than 5\% of the column length, the design rules given by the AA [15] are identical to the design equations for non-welded columns (i.e. the columns are treated as non-welded columns). The design rules in the AS/NAS specification for predicting the design strengths of aluminium columns with transverse weld are identical to the AA, which are detailed in Section 3.4 [16].

EC9 [17] for aluminium structures provides design rules in Section 6.3.1 for aluminium welded columns. In calculating the design strengths of aluminium welded columns, EC9 adopts the HAZ softening factor $\rho_{h a z-E C 9}$ to account for the weakening effects of welding on the column strengths. The values of the HAZ softening factor $\rho_{h a z-E C 9}$ specified in EC9 are equal to 0.46 and 0.48 for the 6063-T5 and 6061-T6 alloys, respectively. The design strength of EC9 for aluminium welded columns $\left(P_{E C 9}\right)$ is shown as Equation (1):

$$
P_{E C 9}=\rho_{h a z-E C 9} \times P_{E C 9-N W}
$$

where $P_{E C 9-N W}$ is the non-welded column compression capacity.

The design strengths of aluminium alloy columns according to the $\mathrm{CN}$ standard [18] $\left(P_{C N}\right)$ equal to the minimum value of compression section capacity $\left(A_{e n} \sigma_{0.2}\right)$ and stability $\left(\bar{\varphi} A \sigma_{0.2}\right)$, where $A$ is the gross cross-sectional area, $A_{e n}$ is effective net cross-section area, $\sigma_{0.2}$ is static $0.2 \%$ proof stress of non-welded materials and $\bar{\varphi}$ is the stability factor. For welded columns, the effective net cross-section area is calculated based on the minimum value of $t_{e, h a z}$ (considering the effect of HAZ softening) and $t_{e}$ (considering the effect of local buckling). The stability coefficient for welded columns $\bar{\varphi}$ is equal to the HAZ softening factor $\left(\rho_{\text {haz-CN }}\right)$ multiplied by the stability coefficient for non-welded columns, and $\rho_{\text {haz-CN }}$ is taken as 0.5 for both 6063-T5 and 6061-T6 alloys. However, 
it should be noted that the stability coefficients provided in the Chinese standard are particularly for biaxial symmetric columns, while the channel section columns considered herein are monosymmetric. The detailed calculation procedure for effective cross-section is codified in Chapter 5 [18] and the design rules for welded columns are given in Chapter 7 [18].

\subsection{DSM for aluminium alloy non-weld columns}

Schafer and Peköz [28] proposed the direct strength method (DSM) approach for cold-formed steel structural members, but not for aluminium alloy structural members. In this study, the appropriateness of DSM for aluminium alloy structural members was assessed. The DSM considered the influences of the global buckling, the coupling effect of the global buckling and local buckling, and the coupling effect of the distortional buckling and component yielding. The DSM approach was codified in the North America Specification [19] for column design. It is considered in this study for comparison purpose.

$$
P_{D S M}=\min \left(P_{n e}, P_{n l}, P_{n d}\right)
$$

Flexural, torsional, or flexural-torsional buckling load $\left(P_{n e}\right)$ is given by:

$$
P_{n e}=\left\{\begin{array}{cc}
\left(0.685^{\lambda_{c}^{2}}\right) P_{y} & \lambda_{c} \leq 1.5 \\
\left(0.877 / \lambda_{c}^{2}\right) P_{y} & \lambda_{c}>1.5
\end{array}\right.
$$

Local buckling load $\left(P_{n l}\right)$ is determined by:

$$
P_{n l}=\left\{\begin{array}{cl}
P_{n e} & \lambda_{l} \leq 0.776 \\
P_{n l}=\left[1-0.15\left(\frac{P_{c r l}}{P_{n e}}\right)^{0.4}\right]\left(\frac{P_{c r l}}{P_{n e}}\right)^{0.4} P_{n e} & \lambda_{l}>0.776
\end{array}\right.
$$

Distortional buckling load $\left(P_{n d}\right)$ is calculated according to:

$$
P_{n d}=\left\{\begin{array}{cc}
P_{y} & \lambda_{d} \leq 0.561 \\
P_{n d}=\left[1-0.25\left(\frac{P_{c r d}}{P_{y}}\right)^{0.6}\right]\left(\frac{P_{c r d}}{P_{y}}\right)^{0.6} P_{y} & \lambda_{d}>0.561
\end{array}\right.
$$

Where

$P_{y}=\sigma_{0.2} A$, is the yield strength of the section;

$P_{c r d}=$ critical value of elastic distortional column buckling load;

$P_{c r e}=$ minimal value of the critical elastic column buckling load for flexural, torsional, or torsional-flexural buckling;

$P_{c r l}=$ critical value of elastic local column buckling load;

$\lambda_{c}=\sqrt{P_{y} / P_{c r e}}$, cross-section slenderness for the flexural, torsional, or flexural-torsional buckling;

$\lambda_{d}=\sqrt{P_{y} / P_{c r d}}$, cross-section slenderness for the distortional buckling; 
$\lambda_{l}=\sqrt{P_{n e} / P_{c r l}}$, cross-section slenderness for the local buckling.

\subsection{Modified DSM for aluminium alloy welded columns}

The DSM design approach described in Section 4.2 was developed for non-welded columns. Later on, Zhu and Young [29] investigated the effects of transverse welds on aluminium column strengths and modified the DSM for aluminium alloy welded CHS columns. The HAZ softening factors for circular hollow section columns proposed by Zhu and Young [29] were modified and used in this study for channel columns. The design strengths $\left(P_{D S M-W}\right)$ is obtained by adjusting the DSM column strengths ( $\left.P_{D S M}\right)$ [19] with the welding reduction factors $\alpha_{1}$ and $\alpha_{2}$, as shown in Equation. (6).

$$
\begin{aligned}
P_{D S M-W} & =\alpha_{1} \alpha_{2} P_{D S M} \\
\alpha_{1} & =1.2(b / t)^{-0.15} \\
\alpha_{2} & =0.4(30 / L)^{-0.18}
\end{aligned}
$$

where $b=$ flat face width of the plate element.

\subsection{CSM for aluminium alloy welded columns}

The continuous strength method (CSM) is a deformation-based design method, which was originally proposed by Gardner and Nethercot [30] for stainless steel hollow members. Later on, Ashraf and Young [12] modified the CSM for welded aluminium columns of square and rectangular hollow sections. The CSM replaces the traditional cross-section classification by a continuous measure of cross-section slenderness $\bar{\lambda}_{p}$ and cross-section deformation capacity $\varepsilon_{L B}$. This study adopts the design rules proposed by Ashraf and Young [12] to predict the strength of welded columns of channel sections, denoted as $P_{C S M-W 1}$.

(1) Determine the cross-section slenderness $\bar{\lambda}_{p}$ for the slenderest element using:

$$
\bar{\lambda}_{p}=\frac{b}{t} \sqrt{\frac{\sigma_{0.2}}{E_{0}}} \sqrt{\frac{4}{k}}
$$

and find the local buckling strain $\varepsilon_{L B}$ using:

$$
\frac{\varepsilon_{L B}}{\varepsilon_{0}}=\frac{3.75}{\bar{\lambda}_{p}^{2.25-0.3 \bar{\lambda}_{p}}}
$$

(2) Obtain the local buckling stress $\sigma_{L B}$ :

$$
\sigma_{L B}=\sigma_{n} \sigma_{0.2}
$$

when $\varepsilon<\varepsilon_{0.2}, \quad \sigma_{n}=\frac{r \cdot \varepsilon_{n}}{1+(r-1) \cdot \varepsilon_{n}^{p}}$

where $r=\frac{E_{0} \varepsilon_{0.2}}{\sigma_{0.2}}$ 


$$
\begin{aligned}
r_{0.2} & =\frac{E_{0.2} \varepsilon_{0.2}}{\sigma_{0.2}} \\
p= & \frac{r\left(1-r_{0.2}\right)}{r-1} \\
E_{0.2} & =\frac{E}{1+0.002 n\left(E / \sigma_{0.2}\right)} \\
\text { when } \varepsilon>\varepsilon_{0.2}, \quad \sigma_{n} & =1+\frac{r_{0.2}\left(\varepsilon_{n}-1\right)}{1+(r-1)\left(\frac{\varepsilon_{n}-1}{\varepsilon_{n u}-1}\right)^{p^{\prime}}} \\
\text { where } r^{\prime} & =\frac{E_{0.2}\left(\varepsilon_{u}-\varepsilon_{0.2}\right)}{\sigma_{u}-\sigma_{0.2}} \\
r_{u} & =\frac{E_{u}\left(\varepsilon_{u}-\varepsilon_{0.2}\right)}{\sigma_{0.2}-\sigma_{0.2}} \\
p^{\prime} & =\frac{r^{\prime}\left(1-r_{u}\right)}{r^{\prime}-1} \\
E_{u} & =\frac{E_{0.2}}{1+\left(r^{\prime}-1\right)\left(1+3.5 \sigma_{0.2} / \sigma_{u}\right)}
\end{aligned}
$$

(3) If the cross-section slenderness $\bar{\lambda}_{p} \leq 1.3$, cross-section effectiveness coefficient $\phi_{\text {eff }}$ equals to 1.0; otherwise, determine cross-section effectiveness coefficient $\phi_{\text {eff }}$ using:

$\phi_{\text {eff }}=-0.09 \bar{\lambda}_{p}+1.09$

(4) Find the buckling reduction factor $\chi$ as suggested by EC9 [17]:

$$
\begin{aligned}
& \chi=\frac{1}{\phi+\sqrt{\phi^{2}-\bar{\lambda}^{2}}}<1.0 \\
& \phi=0.5\left(1+\alpha\left(\bar{\lambda}-\bar{\lambda}_{0}\right)+\bar{\lambda}^{2}\right) \\
& \bar{\lambda}=\sqrt{\frac{A_{e f f} \sigma_{0 \circ 2}}{N_{c r}}}
\end{aligned}
$$

(5) The compression strength predicted by CSM can be calculated as follows:

$$
P_{C S M-W 1}=\phi_{c, h a z} \chi \phi_{e f f} A \sigma_{L B}
$$

Where

$E$ is the Young's modulus of non-welded material;

$E_{0}$ and $E_{u}$ are the tangents at $\sigma_{0.2}$ and $\sigma_{u}$ respectively;

$k$ is the plate buckling coefficient;

$n=\sigma_{0.2} / 10$, is the Ramberg-Osgood exponent;

$N_{c r}$ is the elastic critical buckling force for the relevant buckling mode based on the gross cross-section properties;

$\alpha=0.1$, is an imperfection factor;

$\varepsilon_{n}=\varepsilon / \varepsilon_{0.2}$, is the normalised strain;

$\varepsilon_{0}=\sigma_{0.2} / E$, is the yield strain;

$\kappa$ is a factor to allow for the weakening effects of welding;

$\overline{\lambda_{0}}=0.2$, is the limit of the horizontal plateau; 
$\sigma_{n}=\sigma / \sigma_{0.2}$, is the normalised stress;

$\phi_{c, h a z}=0.72$ is a weakening coefficient.

\subsection{Modified CSM for aluminium alloy welded columns}

$\mathrm{Su}$ et al. [20] proposed the continuous strength method (CSM) for non-welded aluminium alloy stub columns. In this method, the cross-section slenderness $\overline{\lambda_{p}}$ can be defined by Eq. (27). The elastic buckling stress $\sigma_{c r}$ can be determined using approximate formulae or numerical tools, such as CUFSM [31]. This study modified this CSM [20] by introducing a buckling reduction factor $\chi$ as codified in EC9 [17] (see Eq. 23) and a weakening coefficient $\phi_{c, h a z}$. The modified CSM is shown below and validated by the numerical results in this study:

(1) Determine the cross-section slenderness $\overline{\lambda_{p}}$ :

$$
\bar{\lambda}_{p}=\sqrt{\frac{\sigma_{0.2}}{\sigma_{c r}}}
$$

(2) The CSM limiting stress is calculated as:

$$
\sigma_{c s m}=\sigma_{0.2}+E_{s h}\left(\varepsilon_{c s m}-\varepsilon_{0}\right)
$$

(3) The strain hardening modulus is determined from:

$$
E_{s h}=\left(\sigma_{u}-\sigma_{0.2}\right) /\left(0.5 \varepsilon_{u}-\varepsilon_{0}\right)
$$

(4) The deformation capacity of cross sections is as follow:

$$
\frac{\varepsilon_{c s m}}{\varepsilon_{0}}=\left\{\begin{array}{cc}
\frac{0.25}{\bar{\lambda}_{p}^{3.6}}<\min \left(15, \frac{0.5 \varepsilon_{u}}{\varepsilon_{0}}\right) & \overline{\lambda_{p}} \leq 0.68 \\
\frac{1}{\bar{\lambda}_{p}^{1.05}}\left(1-\frac{0.222}{\bar{\lambda}_{p}^{1.05}}\right) & \overline{\lambda_{p}}>0.68
\end{array}\right.
$$

(5) The CSM strength for non-welded column $\left(P_{C S M}\right)$ is:

$$
P_{C S M}= \begin{cases}A \sigma_{c S m} & \overline{\lambda_{p}} \leq 0.68 \\ \frac{\varepsilon_{c s m}}{\varepsilon_{0}} A \sigma_{0.2} & \overline{\lambda_{p}}>0.68\end{cases}
$$

(6) The CSM strength for welded column $\left(P_{C S M-W 2}\right)$ is:

$$
P_{C S M-W 2}=\phi_{c, h a z} \chi P_{C S M}
$$

where $\varepsilon_{u}=0.13\left(1-\sigma_{0.2} / \sigma_{u}\right)+0.059$, is the ultimate strain at ultimate tensile stress;

$\phi_{c, h a z}=0.72$ is a weakening coefficient.

$\chi$ is a buckling reduction factor codified in EC9 [17] 


\section{Comparison of numerical results with design predictions}

The nominal compression strengths of aluminium alloy welded columns of channel sections are predicted by the AA Specification [15] $\left(P_{A A}\right)$, AS/NZS Standard [16] ( $\left.P_{A S / N A S}\right)$, European Code [17] $\left(P_{E C 9}\right)$, Chinese Code [18] ( $\left.P_{C N}\right)$ for aluminium structures, the DSM codified in NAS [19] $\left(P_{D S M}\right)$, the modified DSM ( $\left.P_{D S M-W}\right)$, the CSM proposed by Ashraf and Young [12] ( $\left.P_{C S M-W 1}\right)$ and the modified CSM $\left(P_{C S M-W 2}\right)$. The predicted compression strengths are compared with the numerical strengths obtained from the parametric study $\left(P_{F E}\right)$. The results are summarized in Tables 5-8 for Series P-T5, P-T6, L-T5 and L-T6, respectively. The statistical parameters $P_{m}$ (mean value) and $V_{p}$ (coefficient of variation (COV)) of FE-to-predicted load ratios of each series of specimens were shown in Tables 5-8. Comparisons of FEA results and design predictions are shown in Fig. 6.

For plain channel sections (series P-T5 and P-T6), it is shown that the design strengths predicted by the Chinese Code are the most conservative and scattered: the mean values of load ratio $P_{F E} / P_{C N}$ are 3.24 and 2.77, with the corresponding COV of 0.455 and 0.470 , respectively. It is mainly attributed to the stability coefficients used in the Chinese standard, which are proposed for biaxial symmetric columns but not monosymmetric columns. The predictions of the European Code are also conservative, for which the mean value of load ratio $P_{F E} / P_{E C 9}$ are 1.27 and 1.28 , with the corresponding COV of 0.209 and 0.214 , respectively. The AA and AS/NAS specifications predictions are slightly unconservative, for which the mean value of load ratio $P_{F E} / P_{A A}$ are within the range of $0.95-0.98$. The predictions of the DSM are rather unsafe for plain channel $\left(P_{F E} / P_{D S M}=\right.$ 0.70 and 0.68 for P-T5 and P-T6), this is because the DSM approach was developed based on the cold-formed stainless steel members. The CSM approach proposed by Ashraf and Young [12] yields conservative predictions (the mean value of load ratios $P_{F E} / P_{C S M-W 1}$ are 1.37 and 1.33 for T5 and T6 alloys). The predictions of the aforementioned design methods are rather scatter, with the COVs ranging from 0.151 to 0.470 . The modified DSM yields the most accurate predictions $\left(P_{F E} / P_{D S M-W}\right.$ $=1.14$ and 1.10 for P-T5 and P-T6, respectively), while the modified CSM $\left(P_{C S M-W 2}\right)$ provides most consistent predictions with the corresponding COV of 0.117 and 0.127 for T5 and T6, respectively.

Regarding to lipped channel sections (series L-T5 and L-T6) as summarised in Tables 7-8, the Chinese standard are also found to be the most conservative and scatter, with the mean value of load ratio $P_{F E} / P_{C N}$ to be 2.35 and 2.05 and the COV to be 0.416 and 0.472 , respectively. The EC9 predictions are generally conservative, for which the mean value of load ratio $P_{F E} / P_{E C 9}$ are found to be 1.66 and 1.75 with the COV of 0.378 and 0.326 for T5 and T6 alloys, respectively. The prediction accuracy and scatter level of the AA and AS/NAS are similar. The DSM codified in NAS [19] $\left(P_{D S M}\right)$ is most unconservative, while the modified DSM approach provides the most accurate predictions ( $P_{F E} / P_{D S M-W}=1.20$ and 1.15 for T5 and T6 alloys). The CSM approach proposed by Ashraf and Young [12] are found to be generally conservative and rather scatter, but the modified CSM are the most consistent with the COV of 0.137 and 0.133 for T5 and T6 alloys, respectively. 


\section{Reliability analysis}

The reliability index is an important parameter for the assessment of the reliability level of a design method. In this paper, the reliability of design rules for welded columns is evaluated using reliability analysis. In general, the structure design method is reliable if the reliability index $(\beta)$ is not less than 2.50. The design load combinations used in the reliability analysis are specified as $1.2 \mathrm{D}+1.6 \mathrm{~L}$ for AA [15], 1.25D+1.5L for AS/NZS [16], 1.35D+1.5L for EC9 [17], 1.2D+1.4L for CN [18], where D is the dead load and L represents the live load. The resistance factors of the AA [15], AS/NZS [16], EC9 [17], and CN [18] are specified as $0.85,0.85,0.91$, and 0.83, respectively. For both the DSM and CSM approaches, the load combination was taken as $1.2 \mathrm{D}+1.6 \mathrm{~L}$, and the resistance factor was 0.85 . The reliability index $\beta$ of the design rules are shown in Tables 5-8 for each test series.

For all series, the reliability indexes $\beta$ of the EC9 [17], CN [18], CSM [12], modified DSM and modified CSM approaches were all found to be greater than 2.50 , which are deemed to be reliable for all channel column of normal and high strength aluminium alloys with transverse welds. However, the reliability indexes of the design rules in the AA [15], AS/NZS [16] and DSM [19] approaches were lower than the target value of 2.50. The newly modified DSM and CSM approaches are verified to be reliable design methods for aluminium alloy welded columns of plain and lipped channel sections.

\section{Conclusions}

A numerical investigation and design comparison of aluminium alloy columns of channel sections with transverse welds are presented in this paper. The welding effects on the behaviour of aluminium alloy columns were investigated. Finite element models were developed and validated by ex perimental data. A parametric study was performed using the validated finite element models to generate a total of 100 specimens with the column lengths ranging from 500 to $3500 \mathrm{~mm}$. Both heat-treated aluminium alloys of 6063-T5 and 6061-T6 were considered. The column strengths obtained from the numerical investigation were compared with the design strengths calculated using the existing American, Australian/New Zealand, European and Chinese standards for aluminium structures, as well as the direct strength method (DSM) and the continuous strength method (CSM). A modified DSM and a modified CSM approaches are proposed herein by considering the welding effects. Following comparisons with the numerical results, the existing design methods are generally inaccurate or inconsistent. The modified DSM approach provides the most accurate predictions and the modified CSM approach yields the most consistent results. The reliability of the existing and proposed design rules was evaluated. The American, Australia/New Zealand standards and DSM codified in NAS failed to meet the target reliability level. Both the modified DSM and CSM approaches are found to be reliable. 


\section{Acknowledgements}

We would like to thank the funding support from The University of Hong Kong in the seed funding program for basic research and from the Chinese National Natural Science Foundation (51778370, 51538007) and the Shenzhen science and technology project (JCYJ20170818094820689).

\section{Notations}

\begin{tabular}{|c|c|}
\hline$A$ & gross cross-section area \\
\hline$A_{\text {eff }}, A_{\text {en }}$ & effective area \\
\hline$b$ & flat width of the plate element \\
\hline$B$ & cross-section width \\
\hline$B_{l}$ & stiffener length \\
\hline$E$ & Young's modulus of non-welded materials \\
\hline$E_{W}$ & Young's modulus of welded materials \\
\hline$E_{0}$ & tangents at static $0.2 \%$ proof stress \\
\hline$E_{s h}$ & strain hardening modulus (CSM) \\
\hline$E_{u}$ & tangents at ultimate tensile strength \\
\hline$H$ & cross-section depth \\
\hline$k$ & plate buckling coefficient (CSM) \\
\hline$L$ & column length \\
\hline$n$ & Ramberg-Osgood exponent \\
\hline$N_{c r}$ & elastic critical buckling force \\
\hline$P_{A A}$ & welded column design strengths predicted by the AA \\
\hline$P_{A S / N A S}$ & welded column design strengths predicted by the AS/NAS \\
\hline$P_{C N}$ & welded column design strengths predicted by the $\mathrm{CN}$ \\
\hline$P_{c r d}$ & critical elastic distortional column buckling load (DSM) \\
\hline$P_{\text {cre }}$ & $\begin{array}{l}\text { minimum of the critical elastic column buckling load in flexural, torsional, or } \\
\text { torsional-flexural (DSM) }\end{array}$ \\
\hline$P_{c r l}$ & critical elastic local column buckling load (DSM) \\
\hline$P_{C S M}$ & non-welded column strengths predicted by the CSM [20] \\
\hline$P_{\text {CSM-W1 }}$ & welded column strength calculated using the CSM [12] \\
\hline$P_{\mathrm{CSM}-W 2}$ & welded column strength calculated using the modified CSM \\
\hline$P_{\mathrm{DSM}}$ & column strength predicted by the DSM [19] \\
\hline$P_{\text {DSM-W }}$ & welded column strength calculated using the modified DSM \\
\hline$P_{E C 9}$ & welded column design strengths predicted by EC9 \\
\hline$P_{E C 9-N W}$ & column strength calculated using the EC9 without the consideration of welds \\
\hline$P_{E x p}$ & experimental ultimate loads \\
\hline
\end{tabular}


$P_{F E} \quad$ ultimate loads obtained from FE models

$P_{n d} \quad$ nominal axial strength distortional buckling (DSM)

$P_{n e} \quad$ nominal axial strength for flexural, torsional, or torsional-flexural buckling (DSM)

$P_{n l} \quad$ nominal axial strength local buckling (DSM)

$P_{y} \quad$ yield strength of the section (DSM)

$t \quad$ thickness of element

$\alpha \quad$ imperfection factor (EC9)

$\alpha_{1} \quad$ factor in the proposed design equation due to welding in the modified DSM

$\alpha_{2} \quad$ factor in the proposed design equation due to welding in the modified DSM

$\beta \quad$ reliability index

$\varepsilon_{0} \quad$ yield strain from non-welded tensile coupon

$\varepsilon_{c s m} \quad$ CSM limiting strain

$\varepsilon_{f-w} \quad$ elongation at fracture obtained from welded tensile coupon

$\varepsilon_{L B} \quad$ local buckling stress

$\varepsilon_{n} \quad$ normalised strain

$\varepsilon_{u} \quad$ strain at ultimate of non-welded materials from tensile coupon

$\kappa \quad$ factor to allow for the weakening effects of welding (EC9)

$\bar{\lambda} \quad$ relative slenderness (EC9)

$\bar{\lambda}_{0} \quad$ limit of the horizontal plateau (EC9)

$\lambda_{c} \quad$ cross-section slenderness for the flexural, torsional, or torsional-flexural buckling (DSM)

$\lambda_{d} \quad$ cross-section slenderness for the distortional buckling (DSM)

$\lambda_{l} \quad$ cross-section slenderness for the local buckling (DSM)

$\bar{\lambda}_{p} \quad$ cross-section/plate slenderness (CSM)

$\rho_{\text {haz }-C N} \quad$ heat-affected zone softening factor $(\mathrm{CN})$

$\rho_{\text {haz }-E C 9} \quad$ heat-affected zone softening factor (EC9)

$\sigma_{0.2} \quad 0.2 \%$ proof stress of non-welded material

$\sigma_{0.2-\mathrm{w}} \quad 0.2 \%$ proof stress of welded material

$\sigma_{c r} \quad$ elastic buckling stress

$\sigma_{c s m} \quad$ CSM limiting stress

$\sigma_{n} \quad$ normalised stress

$\sigma_{u} \quad$ ultimate strength of non-welded materials from tensile coupon

$\sigma_{u-w} \quad$ ultimate strength of welded materials from tensile coupon

$\bar{\varphi} \quad$ stability coefficient $(\mathrm{CN})$

$\phi \quad$ resistance factor (EC9)

$\phi_{c, h a z} \quad$ heat-affected zone softening factor

$\phi_{\text {eff }} \quad$ weakening coefficient

$\chi \quad$ reduction factor for the relevant buckling mode (EC9) 


\section{References}

[1] Mazzolani F M. “3D aluminium structures”. Thin-Walled Structures, 2012, 61(6):258-266.

[2] Zhu J H, Young B. "Effects of transverse welds on aluminum alloy columns". Thin-Walled Structures, 2007, 45(3):321-329.

[3] Huang Jihua. "Principles of welding metallurgy". Mechanical Industry Press, 2015.

[4] Lai Y F W, Nethercot D A. "Strength of aluminium members containing local transverse welds". Engineering Structures, 1992, 14(4):241-254.

[5] Zhu J H, Young B. "Experimental investigation of Aluminum Circular Hollow Section Columns". Engineering Structures, 2006,28(2):207 215

[6] Su M N, Young B, Gardner L. "Testing and Design of Aluminum Alloy Cross Sections in Compression”. Journal of Structural Engineering, 2014, 140(9):04014047.

[7] Liu M, Zhang L, Wang P, Chang Y. "Buckling behaviors of section aluminum alloy columns under axial compression". Engineering Structures, 2015, 95:127-137.

[8] Adeoti G O, Fan F, Wang Y, Zhai, X. "Stability of 6082-T6 aluminium alloy columns with H-section and rectangular hollow sections". Thin-Walled Structures, 2015, 89:1-16.

[9] Wang Y, Fan F, Lin S. "Experimental investigation on the stability of aluminium alloy 6082 circular tubes in axial compression”. Thin-Walled Structures, 2015, 89:54-66.

[10] Zhu J H, Young B. "Tests and Design of Aluminum Alloy Compression Members". Journal of Structural Engineering, 2006, 132(7):1096-1107.

[11] Zhu J H, Young B. "Behavior and design of aluminum alloy structural members". Advanced Steel Construction, 2008, 4(2):158-172.

[12] Ashraf M, Young B. "Design formulations for non-welded and welded aluminium columns using Continuous Strength Method”. Engineering Structures, 2011, 33(12):3197-3207.

[13] Wang, T., Hopperstad, O.S., Lademo, O.-G., Larsen, P.K. Finite element analysis of welded beam-to-column joints in aluminium alloy EN AW 6082 T6 (2007) Finite Elements in Analysis and Design, 44 (1-2), pp. 1-16.

[14] De Matteis, G., Naqash, M.T., Brando, G. Effective length of aluminium T-stub connections by parametric analysis (2012) Engineering Structures, 41, pp. 548-561.

[15] Aluminium Association, Aluminium Design Manual, The Aluminium Association, Washington, DC, 2015.

[16] AS/NZS, Aluminium Structures-Part 1: Limit State Design, Australian/New Zealand Standard AS/NZS1664.1:1997. Sydney, Australia: Standards Australia,1997

[17] European Committee for Standardization (EC9), EUROCODE 9: Design of Aluminium Structures-Part 1-1: General Rules and Rules for Buildings, BS EN 1999-1-1:2007, CEN, 2007.

[18] CN. Code for design of aluminium structures. Ministry of Construction of the People's Republic of China. GB50429-2007.

[19] ASCI. North American Specification for the design of cold-formed steel structural members, American Iron and Steel Institute, Washington, DC, 2012, p. 2001.

[20] Su M N, Young B, Gardner L. "The continuous strength method for the design of aluminium alloy structural elements". Engineering Structures, 2016, 122:338-348. 
[21] ABAQUS Analysis User's Manual, version 6.14, ABAQUS Inc., 2014.

[22] Zhu, J.H., Li, Z, Q., Su, M.N., Young, B., "Behaviour of Aluminium Alloys Plain and Lipped Channel Columns", Thin-Walled Struct, submitted.

[23] Sharp M L. "Behaviour and design of aluminum structures". New York: McGraw-Hill; 1993

[24] AS. Methods for tensile testing of metals, Australia Standards, AS 1391-2007, Sydney, Australia: Standards Association of Australia;2007

[25] ASTM. Standard test methods for tension testing of metallic materials, E 8M-97, West Conshohocken, PA: American Society for Testing and Materials; 1997

[26] Zhu JH. Behaviour and design of aluminium alloy structural members. PhD thesis, Department of Civil Engineering, The University of Hong Kong, Hong Kong; 2006.

[27] Zhu J, Wang P, Liu T. "Numerical simulation and design of aluminum compression members with plain and lipped channel sections", Journal of Building Structures, 31 (2010) 163-168.

[28] Schafer, B W, Peköz, T., "Direct Strength Prediction of Cold-Formed Steel Members using Numerical Elastic Buckling Solutions", Thin-walled Struct. (1998).

[29] Zhu, J.H., Young, B., "Numerical investigation and design of aluminum alloy circular hollow section columns", Thin-Walled Struct.46 (12) (2008) 1437-1449.

[30] Gardner L, Nethercot D A. "Structural stainless steel design: A new approach". Structural Engineer, 2004, 82(21):21-28.

[31] Seif M, Schafer B W. "Local buckling of structural steel shapes. Journal of Constructional Steel Research”, 2010, 66(10):1232-1247. 


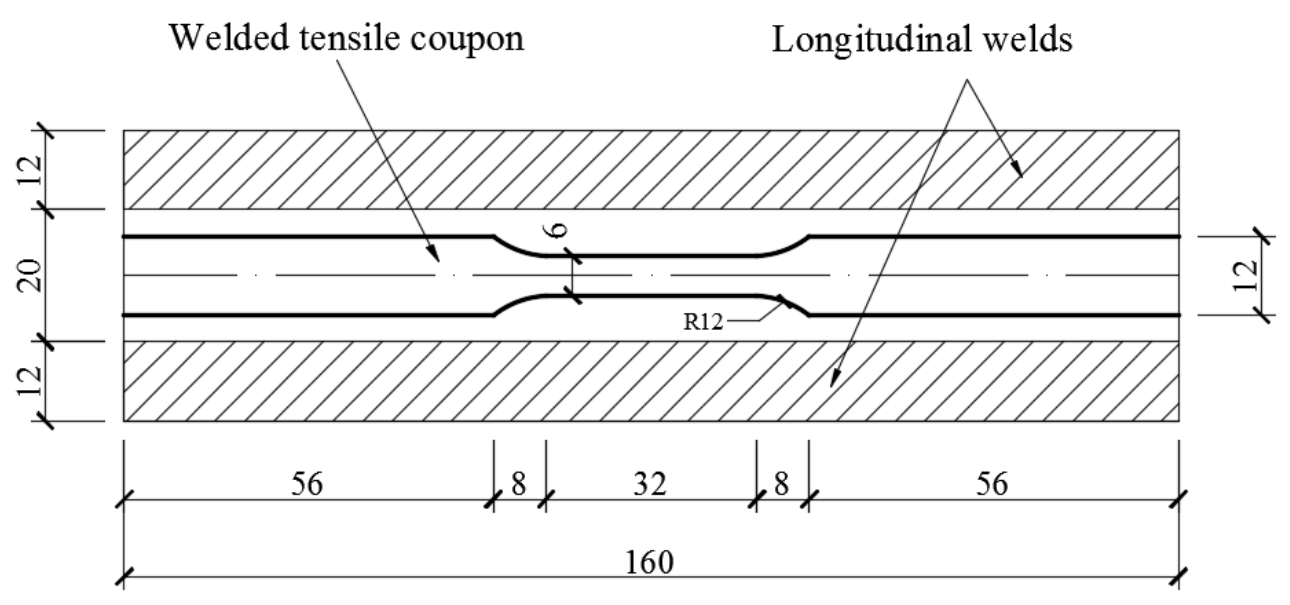

Fig. 1. Welded tensile coupon of $25 \mathrm{~mm}$ gauge length [2] 


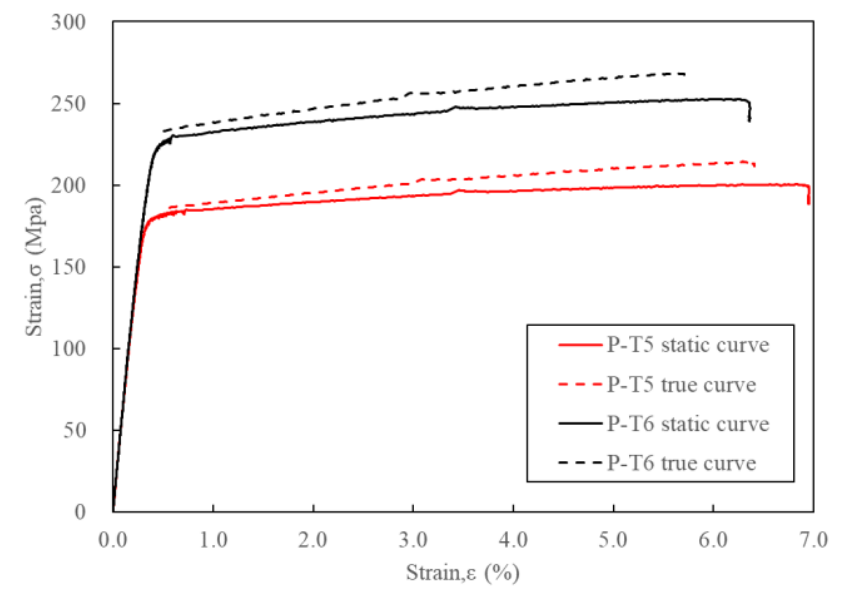

(a) Stress-strain curves of plain channel section columns

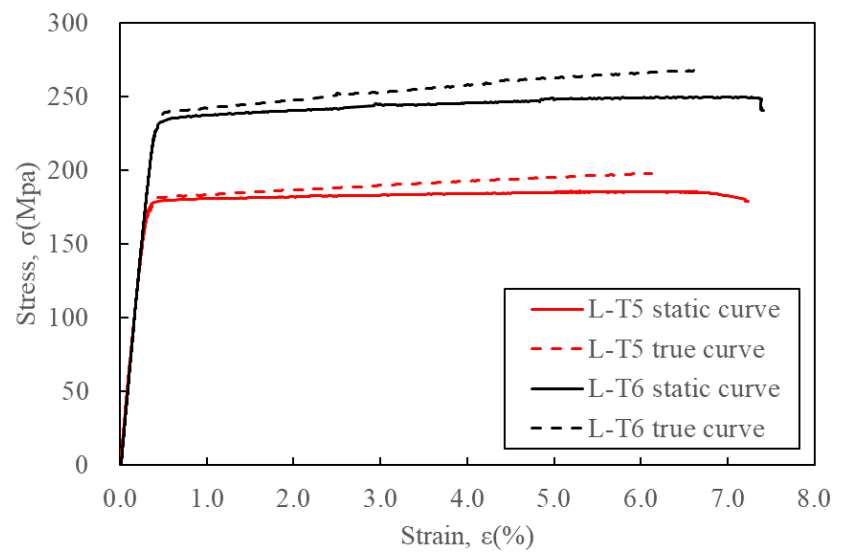

( b ) Stress-strain curves of lipped channel section columns

Fig.2. Material stress-strain curves [22] 


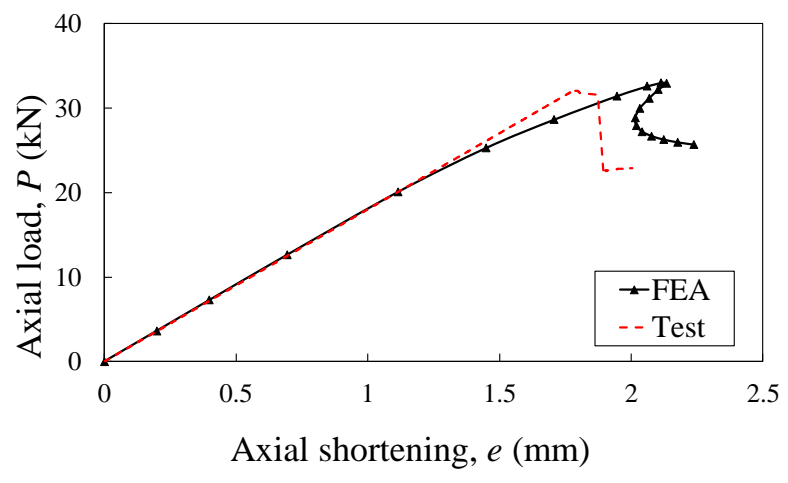

(a) Specimen P-T5-L1350

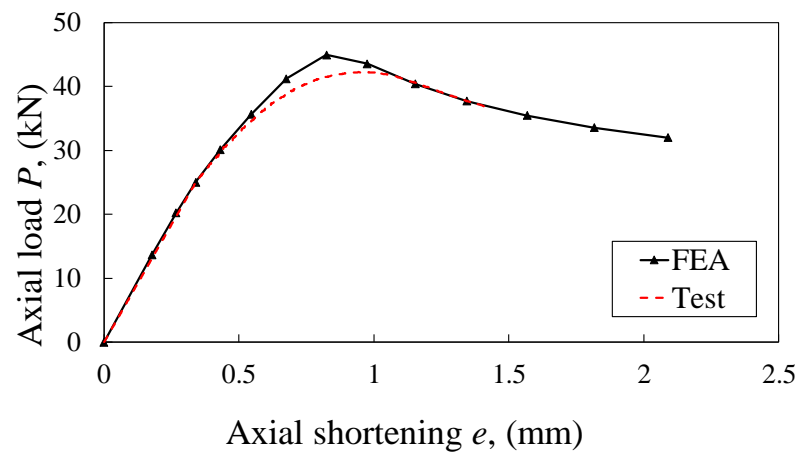

(b) Specimen P-T6-L300

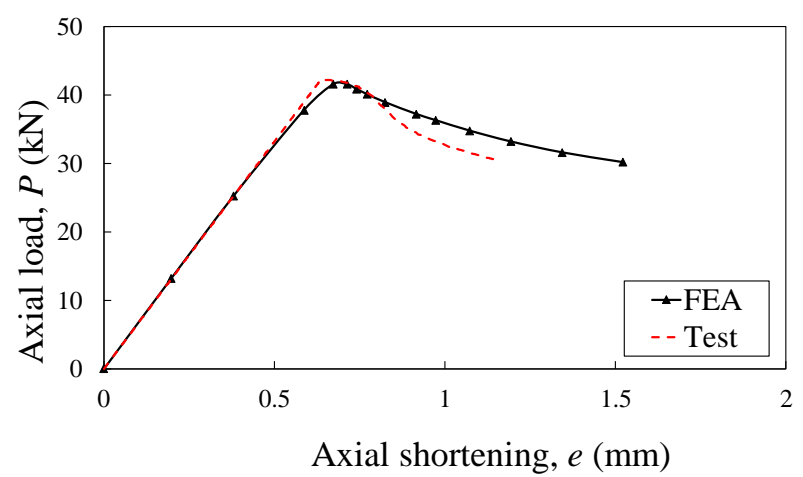

(c) Specimen L-T5-L300

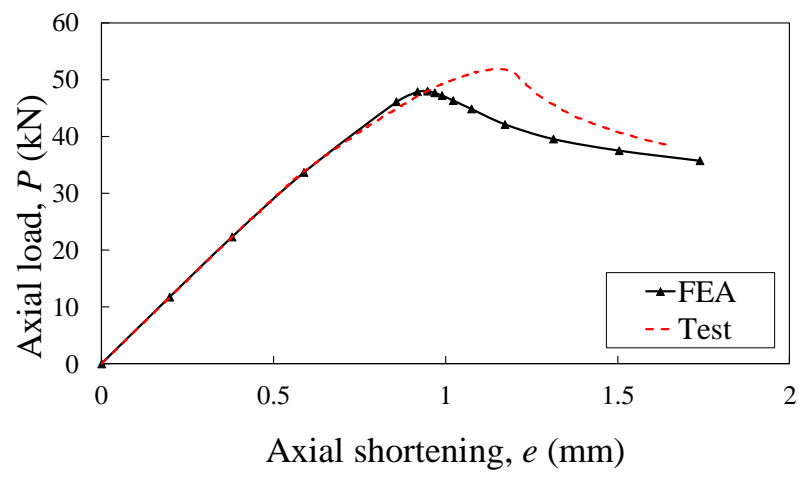

(d) Specimen L-T6-L300

Fig. 3. Comparison of the FEA and test curves [20] 


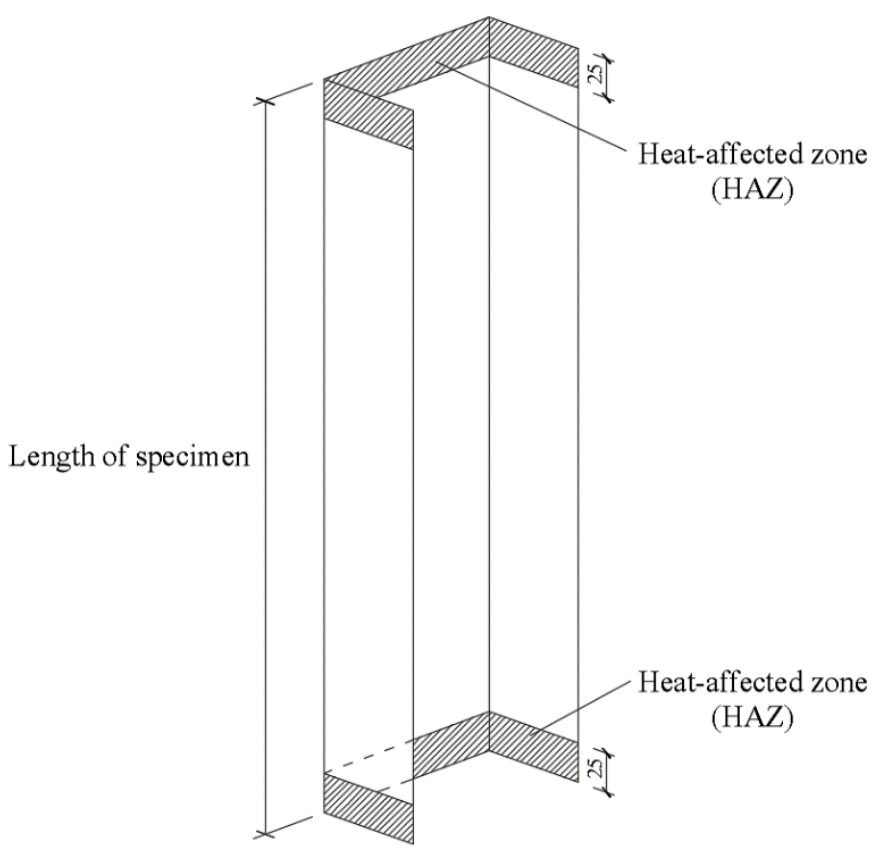

Fig. 4. Schematic diagram of heat-affected zone 


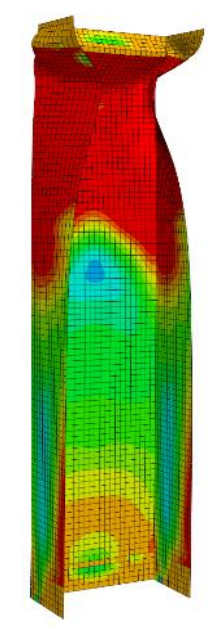

(a)Specimen P-T5-M2-L500 failed by local buckling
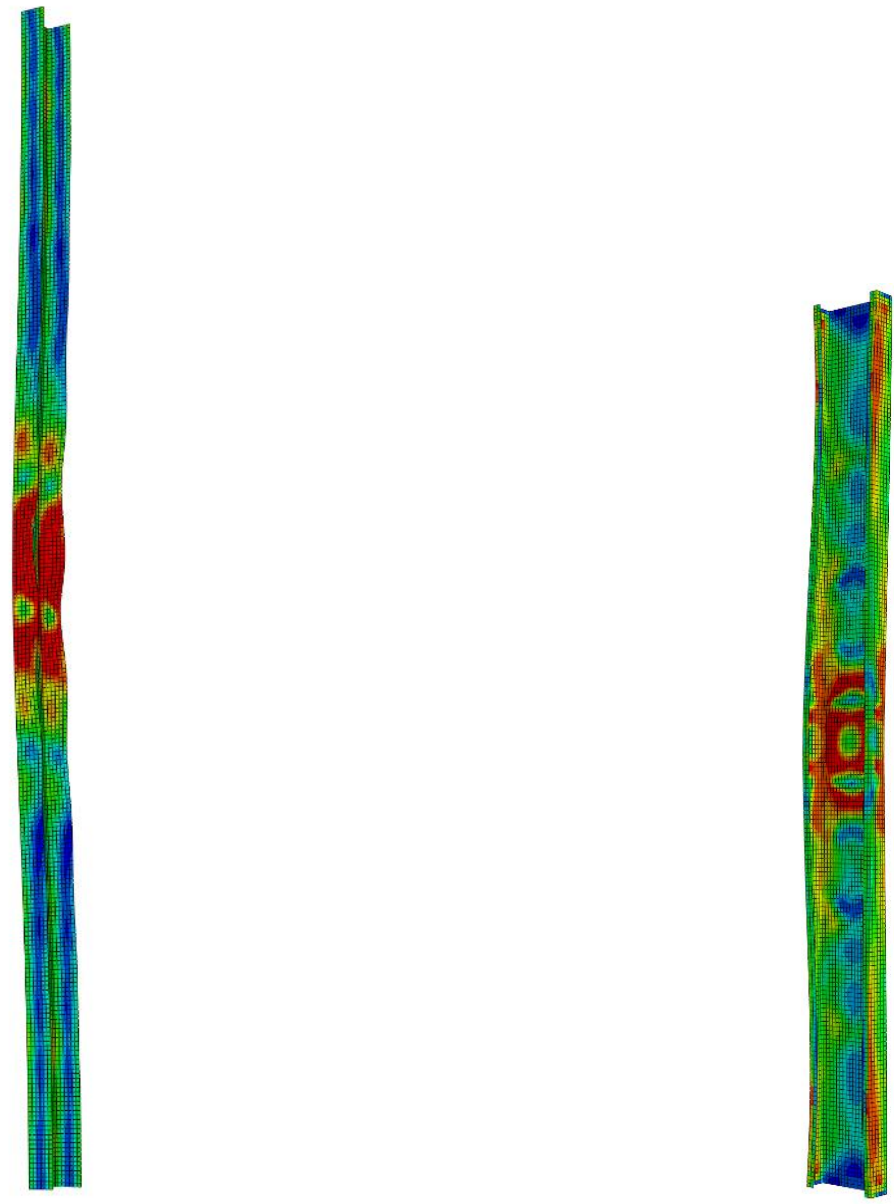

(b)Specimen P-T5-M3-L2700 failed by flexural buckling

(c)Specimen L-T5-M5-L2000 failed by distortional buckling

Fig. 5. Failure modes obtained from the FE models 


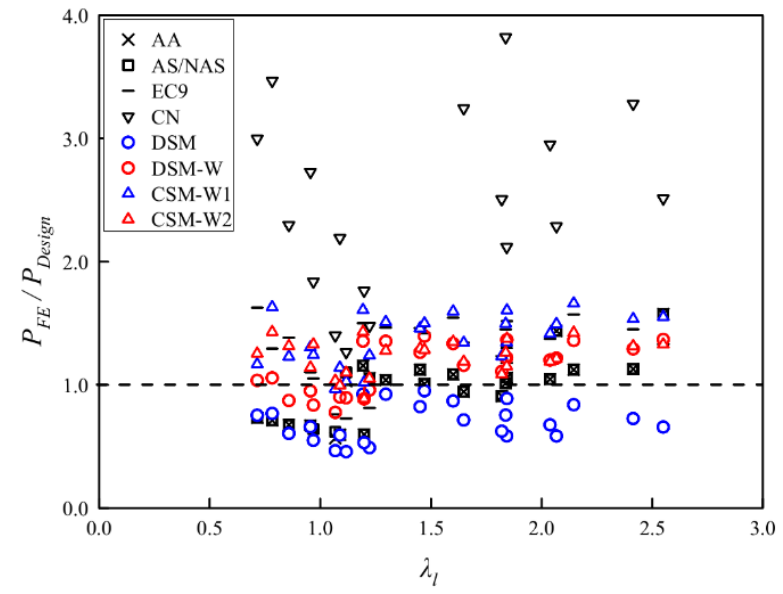

(a) Series P-T5

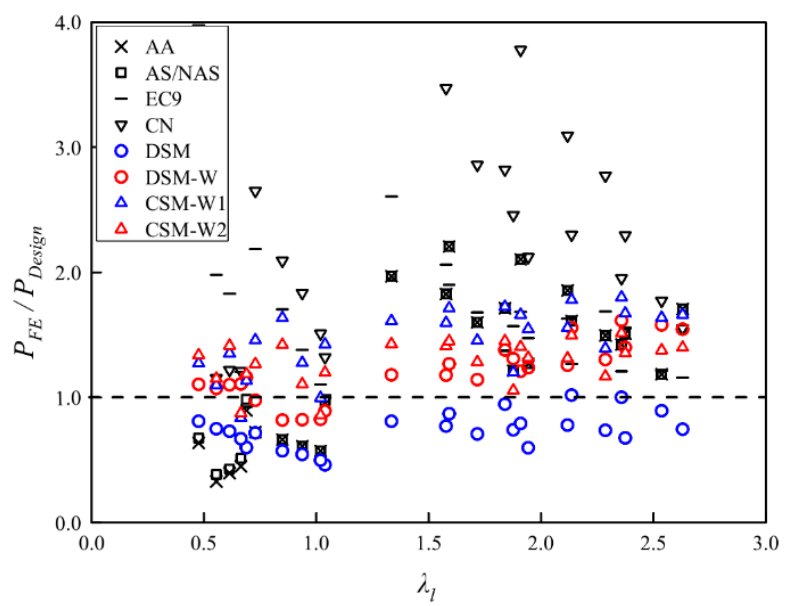

(c) Series L-T5

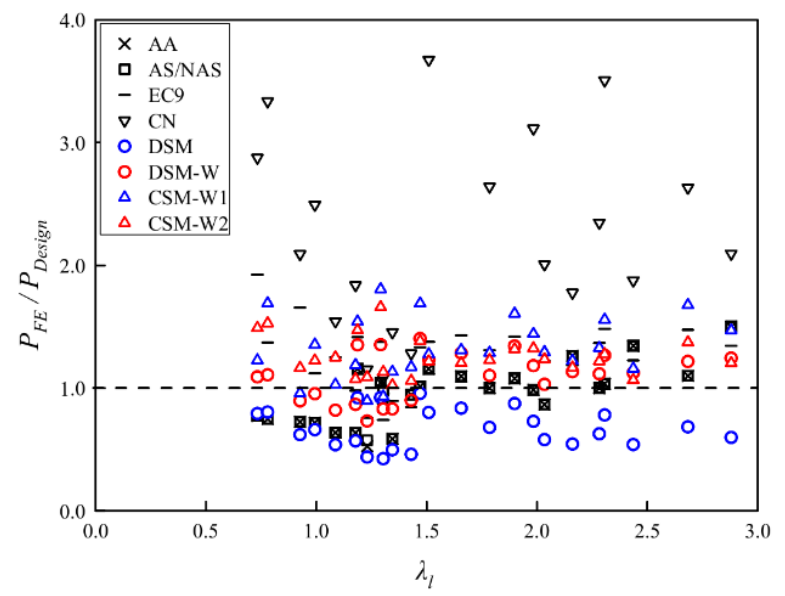

(b) Series P-T6

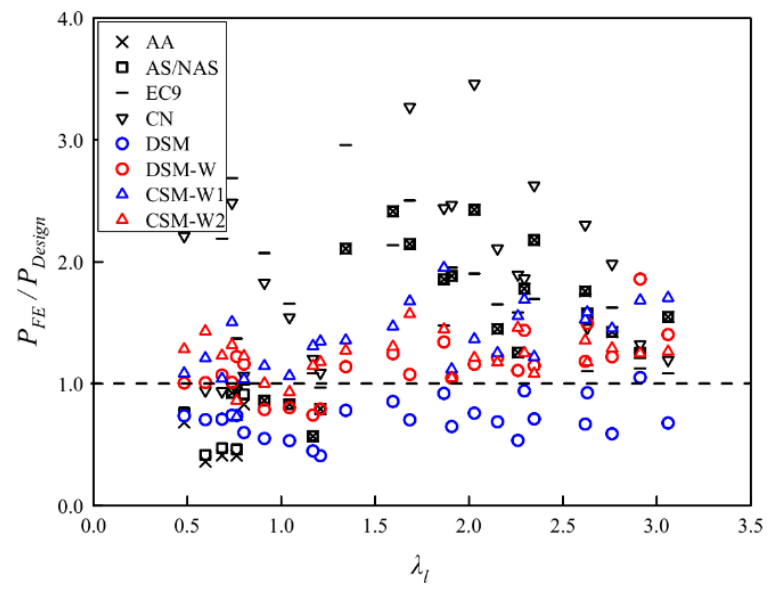

(d) Series L-T6

Fig. 6. Comparisons of numerical ultimate strengths with design predictions 
Table 1. Measured welded material properties from tensile coupons tests

\begin{tabular}{ccccc}
\hline $\begin{array}{c}\text { Series of } \\
\text { specimens }\end{array}$ & $E_{W}(G P a)$ & $\sigma_{0.2-\mathrm{W}}(\mathrm{MPa})$ & $\sigma_{\mathrm{u}-\mathrm{W}}(M P a)$ & $\varepsilon_{f-W}(\%)$ \\
\hline P-T5 & 65.5 & 72.1 & 156.4 & 10.4 \\
P-T6 & 66.6 & 86.7 & 176.3 & 7.8 \\
L-T5 & 65.5 & 82.5 & 140.4 & 8.1 \\
L-T6 & 65.6 & 111.3 & 172.4 & 6.5 \\
\hline
\end{tabular}


Table 2. Comparison of test and FEA results for non-welded columns of plain channel sections [22]

\begin{tabular}{|c|c|c|c|c|c|}
\hline \multirow[b]{2}{*}{ Specimen } & \multicolumn{2}{|c|}{ Experimental } & \multicolumn{2}{|c|}{ FEA } & \multirow{2}{*}{$\frac{\text { Comparison }}{P_{E x p} / P_{F E}}$} \\
\hline & $P_{E x p}(k N)$ & Failure modes & $P_{F E}(k N)$ & $\begin{array}{c}\text { Failure } \\
\text { modes }\end{array}$ & \\
\hline P-T5-86×50×1.9-L300 & 41.6 & $\mathrm{~L}$ & 38.4 & $\mathrm{~L}$ & 1.08 \\
\hline P-T5-86×50×1.9-L800 & 37.4 & $\mathrm{~L}$ & 34.9 & $\mathrm{~L}$ & 1.07 \\
\hline P-T5-86×50×1.9-L1350 & 33.5 & $\mathrm{~L}+\mathrm{F}$ & 33.0 & $\mathrm{~L}$ & 1.02 \\
\hline P-T5-86×50×1.9-L1350\# & 31.9 & $\mathrm{~L}+\mathrm{F}$ & 33.0 & $\mathrm{~L}+\mathrm{F}$ & 0.97 \\
\hline P-T5-86×50×1.9-L1900 & 26.5 & $\mathrm{~L}+\mathrm{F}$ & 29.0 & $\mathrm{~L}+\mathrm{F}$ & 0.91 \\
\hline P-T5-86×50×1.9-L2450 & 23.1 & $\mathrm{~L}+\mathrm{F}+\mathrm{FT}$ & 24.3 & $\mathrm{~F}+\mathrm{FT}+\mathrm{L}$ & 0.95 \\
\hline P-T5-86×50×1.9-L3000 & 16.2 & $\mathrm{~L}+\mathrm{F}+\mathrm{FT}$ & 19.4 & $\mathrm{~F}+\mathrm{FT}$ & 0.84 \\
\hline P-T6-86×50×1.9-L300 & 45.4 & $\mathrm{~L}$ & 44.9 & $\mathrm{~L}$ & 1.01 \\
\hline P-T6-86×50×1.9-L800 & 41.3 & $\mathrm{~L}$ & 42.7 & $\mathrm{~L}$ & 0.97 \\
\hline P-T6-86×50×1.9-L1350 & 34.4 & $\mathrm{~L}+\mathrm{F}$ & 35.7 & $\mathrm{~L}$ & 0.96 \\
\hline P-T6-86×50×1.9-L1900 & 27.0 & $\mathrm{~L}+\mathrm{F}$ & 28.0 & $\mathrm{~L}+\mathrm{F}$ & 0.96 \\
\hline P-T6-86×50×1.9-L1900\# & 25.9 & $\mathrm{~L}+\mathrm{F}$ & 27.9 & $\mathrm{~L}+\mathrm{F}$ & 0.93 \\
\hline P-T6-86×50×1.9-L2450 & 23.2 & $\mathrm{~L}+\mathrm{F}+\mathrm{FT}$ & 23.7 & $\mathrm{~L}+\mathrm{F}+\mathrm{FT}$ & 0.98 \\
\hline \multirow[t]{3}{*}{ P-T6-86×50×1.9-L3000 } & 18.6 & $\mathrm{~L}+\mathrm{F}+\mathrm{FT}$ & 17.9 & $\mathrm{~F}$ & 1.04 \\
\hline & & & & Mean & 0.98 \\
\hline & & & & $\mathrm{COV}$ & 0.065 \\
\hline
\end{tabular}

Note: 'L' represents local buckling; 'F' represents flexural buckling; 'FT' represents flexural-torsion buckling 
Table 3. Comparison of test and FEA results for non-welded columns of lipped channel sections [27]

\begin{tabular}{|c|c|c|c|c|c|}
\hline \multirow[b]{2}{*}{ Specimens } & \multicolumn{2}{|c|}{ Experimental } & \multicolumn{2}{|c|}{ FEA } & \multirow{2}{*}{$\frac{\text { Comparison }}{P_{E x p} / P_{F E}}$} \\
\hline & $P_{E x p}(k N)$ & $\begin{array}{l}\text { Failure } \\
\text { modes }\end{array}$ & $P_{F E}(k N)$ & $\begin{array}{l}\text { Failure } \\
\text { modes }\end{array}$ & \\
\hline L-T5-86×50×1.9-L300 & 42.2 & $\mathrm{~L}$ & 41.6 & $\mathrm{~L}$ & 1.01 \\
\hline L-T5-86×50×1.9-L800 & 39.4 & $\mathrm{~L}+\mathrm{FT}$ & 38.6 & $\mathrm{~L}$ & 1.02 \\
\hline L-T5-86×50×1.9-L1350 & 35.3 & $\mathrm{~L}+\mathrm{FT}$ & 35.9 & $\mathrm{~F}+\mathrm{L}$ & 0.98 \\
\hline L-T5-86×50×1.9-L1350\# & 32.1 & $\mathrm{~L}+\mathrm{FT}$ & 35.5 & $\mathrm{~F}+\mathrm{L}$ & 0.90 \\
\hline L-T5-86×50×1.9-L1900 & 26.0 & $\mathrm{~F}+\mathrm{L}$ & 30.6 & $\mathrm{~F}+\mathrm{L}$ & 0.85 \\
\hline L-T5-86×50×1.9-L2450 & 16.9 & FT & 22.3 & $\mathrm{~F}+\mathrm{L}$ & 0.76 \\
\hline L-T5-86×50×1.9-L3000 & 12.8 & FT & 16.5 & $\mathrm{~F}+\mathrm{L}$ & 0.78 \\
\hline L-T6-86×50×1.9-L300 & 50.4 & $\mathrm{~L}$ & 48.0 & $\mathrm{~L}$ & 1.05 \\
\hline L-T6-86×50×1.9-L800 & 48.8 & $\mathrm{~L}$ & 45.8 & $\mathrm{~L}$ & 1.07 \\
\hline L-T6-86×50×1.9-L1350 & 42.9 & $\mathrm{~L}+\mathrm{FT}$ & 41.0 & $\mathrm{~F}+\mathrm{L}$ & 1.05 \\
\hline L-T6-86×50×1.9-L1900 & 27.1 & $\mathrm{~L}+\mathrm{FT}$ & 31.9 & $\mathrm{~F}+\mathrm{L}$ & 0.85 \\
\hline L-T6-86×50×1.9-L1900\# & 27.0 & $\mathrm{~L}+\mathrm{FT}$ & 32.7 & $\mathrm{~F}+\mathrm{L}$ & 0.83 \\
\hline L-T6-86×50×1.9-L2450 & 17.4 & FT & 22.0 & $\mathrm{~F}+\mathrm{FT}+\mathrm{L}$ & 0.79 \\
\hline \multirow[t]{3}{*}{ L-T6-86×50×1.9-L3000 } & 13.2 & FT & 15.1 & $\mathrm{~F}+\mathrm{FT}$ & 0.87 \\
\hline & & & & Mean & 0.92 \\
\hline & & & & $\mathrm{COV}$ & 0.121 \\
\hline
\end{tabular}

Note: 'L' represents local buckling; 'F' represents flexural buckling; 'FT' represents flexural-torsion buckling 
Table 4. Dimensions of cross-sections used in parametric study

\begin{tabular}{ccccccccc}
\hline $\begin{array}{c}\text { Specimen } \\
\text { sections }\end{array}$ & $\begin{array}{c}H \\
(\mathrm{~mm})\end{array}$ & $\begin{array}{c}B \\
(\mathrm{~mm})\end{array}$ & $\begin{array}{c}\text { Specimen } \\
(\mathrm{mm})\end{array}$ & $\begin{array}{c}H \\
\text { sections }\end{array}$ & $\begin{array}{c}B \\
(\mathrm{~mm})\end{array}$ & $\begin{array}{c}B_{l} \\
(\mathrm{~mm})\end{array}$ & $\begin{array}{c}t \\
(\mathrm{~mm})\end{array}$ & \begin{tabular}{c} 
(mm) \\
\hline P-T5-M1
\end{tabular} \\
\hline 60 & 60 & 3 & L-T5-M1 & 60 & 60 & 15 & 3 \\
P-T5-M2 & 120 & 60 & 3 & L-T5-M2 & 120 & 60 & 15 & 3 \\
P-T5-M3 & 120 & 60 & 2 & L-T5-M3 & 120 & 60 & 10 & 3 \\
P-T5-M4 & 160 & 60 & 2 & L-T5-M4 & 160 & 60 & 10 & 3 \\
P-T5-M5 & 200 & 60 & 2 & L-T5-M5 & 200 & 60 & 20 & 3 \\
P-T6-M1 & 60 & 60 & 3 & L-T6-M1 & 60 & 60 & 15 & 3 \\
P-T6-M2 & 120 & 60 & 3 & L-T6-M2 & 120 & 60 & 15 & 3 \\
P-T6-M3 & 120 & 60 & 2 & L-T6-M3 & 120 & 60 & 10 & 3 \\
P-T6-M4 & 160 & 60 & 2 & L-T6-M4 & 160 & 60 & 10 & 3 \\
P-T6-M5 & 200 & 60 & 2 & L-T6-M5 & 200 & 60 & 20 & 3 \\
\hline
\end{tabular}


Table 5. Comparison between numerical results and design predictions for series P-T5

\begin{tabular}{|c|c|c|c|c|c|c|c|c|c|}
\hline \multirow[b]{2}{*}{ Specimen } & \multirow{2}{*}{$\begin{array}{c}\text { FEA } \\
P_{F E}(k N)\end{array}$} & \multicolumn{8}{|c|}{ Comparison } \\
\hline & & $\frac{P_{F E}}{P_{A A}}$ & $\frac{P_{F E}}{P_{A S / N A S}}$ & $\frac{P_{F E}}{P_{E C 9}}$ & $\frac{P_{F E}}{P_{C N}}$ & $\frac{P_{F E}}{P_{D S M}}$ & $\frac{P_{F E}}{P_{D S M-W}}$ & $\frac{P_{F E}}{P_{C S M-W 1}}$ & $\frac{P_{F E}}{P_{C S M-\mathrm{W} 2}}$ \\
\hline P-T5-M1-W-L500 & 33.7 & 1.03 & 1.10 & 0.73 & 1.27 & 0.46 & 0.90 & 1.03 & 1.10 \\
\hline P-T5-M1-W-L1200 & 32.2 & 0.57 & 0.62 & 0.76 & 1.40 & 0.47 & 0.78 & 0.97 & 1.03 \\
\hline P-T5-M1-W-L2000 & 33.4 & 0.60 & 0.64 & 1.05 & 1.84 & 0.55 & 0.84 & 1.25 & 1.33 \\
\hline P-T5-M1-W-L2700 & 31.1 & 0.68 & 0.68 & 1.38 & 2.30 & 0.61 & 0.87 & 1.23 & 1.32 \\
\hline P-T5-M1-W-L3500 & 28.3 & 0.73 & 0.73 & 1.63 & 3.00 & 0.75 & 1.04 & 1.17 & 1.25 \\
\hline P-T5-M2-W-L500 & 45.5 & 1.06 & 1.06 & 0.81 & 1.48 & 0.49 & 0.96 & 1.24 & 1.05 \\
\hline P-T5-M2-W-L1200 & 45.4 & 0.60 & 0.60 & 0.88 & 1.77 & 0.53 & 0.89 & 1.02 & 0.89 \\
\hline P-T5-M2-W-L2000 & 43.9 & 0.60 & 0.60 & 0.99 & 2.19 & 0.59 & 0.90 & 1.14 & 1.00 \\
\hline P-T5-M2-W-L2700 & 40.6 & 0.67 & 0.67 & 1.10 & 2.73 & 0.66 & 0.95 & 1.31 & 1.14 \\
\hline P-T5-M2-W-L3500 & 36.2 & 0.71 & 0.71 & 1.30 & 3.47 & 0.77 & 1.06 & 1.63 & 1.43 \\
\hline P-T5-M3-W-L500 & 27.4 & 1.34 & 1.34 & 1.18 & 2.12 & 0.59 & 1.22 & 1.35 & 1.15 \\
\hline P-T5-M3-W-L1200 & 26.9 & 0.91 & 0.91 & 1.23 & 2.51 & 0.62 & 1.11 & 1.23 & 1.09 \\
\hline P-T5-M3-W-L2000 & 26.8 & 0.94 & 0.94 & 1.34 & 3.25 & 0.72 & 1.16 & 1.34 & 1.19 \\
\hline P-T5-M3-W-L2700 & 26.1 & 1.12 & 1.12 & 1.46 & 4.28 & 0.82 & 1.27 & 1.46 & 1.30 \\
\hline P-T5-M3-W-L3500 & 22.6 & 1.16 & 1.16 & 1.50 & 5.30 & 0.93 & 1.36 & 1.61 & 1.43 \\
\hline P-T5-M4-W-L500 & 29.7 & 1.44 & 1.44 & 1.24 & 2.29 & 0.59 & 1.22 & 1.50 & 1.21 \\
\hline P-T5-M4-W-L1200 & 31.0 & 1.05 & 1.05 & 1.37 & 2.95 & 0.68 & 1.20 & 1.42 & 1.19 \\
\hline P-T5-M4-W-L2000 & 30.0 & 1.01 & 1.01 & 1.45 & 3.82 & 0.76 & 1.23 & 1.50 & 1.26 \\
\hline P-T5-M4-W-L2700 & 28.8 & 1.09 & 1.09 & 1.55 & 5.04 & 0.87 & 1.34 & 1.60 & 1.35 \\
\hline P-T5-M4-W-L3500 & 23.2 & 1.04 & 1.04 & 1.47 & 5.83 & 0.92 & 1.36 & 1.51 & 1.28 \\
\hline P-T5-M5-W-L500 & 32.4 & 1.58 & 1.58 & 1.33 & 2.51 & 0.66 & 1.37 & 1.55 & 1.33 \\
\hline P-T5-M5-W-L1200 & 33.4 & 1.13 & 1.13 & 1.45 & 3.28 & 0.73 & 1.29 & 1.54 & 1.32 \\
\hline P-T5-M5-W-L2000 & 33.2 & 1.12 & 1.12 & 1.57 & 4.49 & 0.84 & 1.36 & 1.66 & 1.42 \\
\hline P-T5-M5-W-L2700 & 29.0 & 1.06 & 1.06 & 1.52 & 5.49 & 0.89 & 1.37 & 1.61 & 1.38 \\
\hline P-T5-M5-W-L3500 & 23.2 & 1.01 & 1.01 & 1.42 & 6.34 & 0.95 & 1.40 & 1.50 & 1.29 \\
\hline Mean, $P_{m}$ & & 0.97 & 0.98 & 1.27 & 3.24 & 0.70 & 1.14 & 1.37 & 1.23 \\
\hline $\mathrm{COV}, V_{p}$ & & 0.279 & 0.273 & 0.209 & 0.455 & 0.215 & 0.177 & 0.151 & 0.117 \\
\hline Resistance factor, $\phi$ & & 0.85 & 0.85 & 0.91 & 0.83 & 0.85 & 0.85 & 0.85 & 0.85 \\
\hline Reliability index, $\beta$ & & 2.02 & 2.08 & 2.86 & 3.76 & 0.99 & 2.75 & 3.73 & 3.57 \\
\hline
\end{tabular}


Table 6. Comparison between numerical results and design predictions for series P-T6

\begin{tabular}{|c|c|c|c|c|c|c|c|c|c|}
\hline \multirow{3}{*}{ Specimen } & \multirow{3}{*}{$\begin{array}{c}\text { FEA } \\
P_{F E}(k N)\end{array}$} & \multicolumn{8}{|c|}{ Comparison } \\
\hline & & $P_{F E}$ & $P_{F E}$ & $P_{F E}$ & $P_{F E}$ & $P_{F E}$ & $P_{F E}$ & $P_{F E}$ & $P_{F E}$ \\
\hline & & $\overline{P_{A A}}$ & $\overline{P_{A S / N A S}}$ & $\overline{P_{E C 9}}$ & $\overline{P_{C N}}$ & $\overline{P_{D S M}}$ & $\overline{P_{D S M-W}}$ & $\overline{P_{C S M-W 1}}$ & $\overline{P_{C S M-\mathrm{W} 2}}$ \\
\hline P-T6-M1-W-L500 & 34.9 & 0.91 & 0.98 & 0.74 & 1.08 & 0.43 & 0.83 & 0.93 & 1.13 \\
\hline P-T6-M1-W-L1200 & 33.4 & 0.53 & 0.58 & 0.76 & 1.15 & 0.44 & 0.73 & 0.90 & 1.09 \\
\hline P-T6-M1-W-L2000 & 34.8 & 0.64 & 0.64 & 1.25 & 1.54 & 0.54 & 0.82 & 1.03 & 1.25 \\
\hline P-T6-M1-W-L2700 & 32.4 & 0.73 & 0.73 & 1.66 & 2.09 & 0.62 & 0.90 & 0.96 & 1.17 \\
\hline P-T6-M1-W-L3500 & 29.0 & 0.77 & 0.77 & 1.93 & 2.88 & 0.79 & 1.09 & 1.23 & 1.49 \\
\hline P-T6-M2-W-L500 & 47.7 & 0.95 & 0.95 & 0.85 & 1.28 & 0.46 & 0.90 & 1.17 & 1.06 \\
\hline P-T6-M2-W-L1200 & 47.5 & 0.59 & 0.59 & 0.90 & 1.45 & 0.50 & 0.83 & 1.13 & 1.02 \\
\hline P-T6-M2-W-L2000 & 45.7 & 0.64 & 0.64 & 0.98 & 1.84 & 0.57 & 0.87 & 1.19 & 1.07 \\
\hline P-T6-M2-W-L2700 & 42.3 & 0.72 & 0.72 & 1.12 & 2.49 & 0.66 & 0.95 & 1.35 & 1.22 \\
\hline P-T6-M2-W-L3500 & 37.0 & 0.75 & 0.75 & 1.37 & 3.34 & 0.81 & 1.11 & 1.69 & 1.53 \\
\hline P-T6-M3-W-L500 & 28.2 & 1.26 & 1.26 & 1.19 & 1.78 & 0.55 & 1.13 & 1.22 & 1.17 \\
\hline P-T6-M3-W-L1200 & 27.8 & 0.87 & 0.87 & 1.22 & 2.01 & 0.58 & 1.03 & 1.29 & 1.23 \\
\hline P-T6-M3-W-L2000 & 27.6 & 1.00 & 1.00 & 1.31 & 2.64 & 0.68 & 1.10 & 1.29 & 1.23 \\
\hline P-T6-M3-W-L2700 & 26.2 & 1.16 & 1.16 & 1.38 & 3.67 & 0.80 & 1.23 & 1.28 & 1.22 \\
\hline P-T6-M3-W-L3500 & 22.0 & 1.16 & 1.16 & 1.42 & 4.72 & 0.92 & 1.35 & 1.54 & 1.47 \\
\hline P-T6-M4-W-L500 & 29.9 & 1.34 & 1.34 & 1.23 & 1.88 & 0.54 & 1.12 & 1.16 & 1.07 \\
\hline P-T6-M4-W-L1200 & 32.0 & 1.00 & 1.00 & 1.37 & 2.35 & 0.63 & 1.12 & 1.33 & 1.22 \\
\hline P-T6-M4-W-L2000 & 31.1 & 0.99 & 0.99 & 1.42 & 3.11 & 0.73 & 1.18 & 1.44 & 1.32 \\
\hline P-T6-M4-W-L2700 & 28.3 & 1.10 & 1.10 & 1.43 & 4.23 & 0.84 & 1.29 & 1.31 & 1.21 \\
\hline P-T6-M4-W-L3500 & 22.6 & 1.04 & 1.04 & 1.38 & 5.19 & 0.92 & 1.35 & 1.81 & 1.66 \\
\hline P-T6-M5-W-L500 & 33.4 & 1.50 & 1.50 & 1.35 & 2.10 & 0.60 & 1.25 & 1.47 & 1.20 \\
\hline P-T6-M5-W-L1200 & 35.0 & 1.10 & 1.10 & 1.47 & 2.63 & 0.69 & 1.22 & 1.68 & 1.37 \\
\hline P-T6-M5-W-L2000 & 33.0 & 1.03 & 1.03 & 1.48 & 3.51 & 0.78 & 1.27 & 1.56 & 1.28 \\
\hline P-T6-M5-W-L2700 & 28.8 & 1.08 & 1.08 & 1.42 & 4.65 & 0.87 & 1.34 & 1.61 & 1.32 \\
\hline P-T6-M5-W-L3500 & 22.7 & 1.01 & 1.01 & 1.33 & 5.63 & 0.96 & 1.40 & 1.69 & 1.38 \\
\hline Mean, $P_{m}$ & & 0.95 & 0.96 & 1.28 & 2.77 & 0.68 & 1.10 & 1.33 & 1.26 \\
\hline $\mathrm{COV}, V_{p}$ & & 0.255 & 0.250 & 0.214 & 0.470 & 0.236 & 0.179 & 0.190 & 0.127 \\
\hline Resistance factor, $\phi$ & & 0.85 & 0.85 & 0.91 & 0.83 & 0.85 & 0.85 & 0.85 & 0.85 \\
\hline Reliability index, $\beta$ & & 2.09 & 2.15 & 2.85 & 3.38 & 0.85 & 2.62 & 3.30 & 3.58 \\
\hline
\end{tabular}


Table 7. Comparison between numerical results and design predictions for series L-T5

\begin{tabular}{|c|c|c|c|c|c|c|c|c|c|}
\hline \multirow{3}{*}{ Specimen } & \multirow{3}{*}{$\begin{array}{c}\text { FEA } \\
P_{F E}(k N)\end{array}$} & \multicolumn{8}{|c|}{ Comparison } \\
\hline & & $P_{F E}$ & $P_{F E}$ & $P_{F E}$ & $P_{F E}$ & $P_{F E}$ & $P_{F E}$ & $P_{F E}$ & $P_{F E}$ \\
\hline & & $\overline{P_{A A}}$ & $\overline{P_{A S / N A S}}$ & $\overline{P_{E C 9}}$ & $\overline{P_{C N}}$ & $\overline{P_{D S M}}$ & $\overline{P_{D S M-W}}$ & $\overline{P_{C S M-W 1}}$ & $\overline{P_{C S M-W 2}}$ \\
\hline L-T5-M1-W-L500 & 43.1 & 0.90 & 0.99 & 0.92 & 1.14 & 0.60 & 1.16 & 1.13 & 1.19 \\
\hline L-T5-M1-W-L1200 & 40.8 & 0.45 & 0.51 & 1.21 & 1.21 & 0.67 & 1.11 & 0.84 & 0.88 \\
\hline L-T5-M1-W-L2000 & 33.9 & 0.39 & 0.43 & 1.83 & 1.22 & 0.73 & 1.10 & 1.35 & 1.41 \\
\hline L-T5-M1-W-L2700 & 24.9 & 0.33 & 0.38 & 1.98 & 1.15 & 0.75 & 1.07 & 1.10 & 1.15 \\
\hline L-T5-M1-W-L3500 & 36.8 & 0.64 & 0.67 & 3.98 & 2.37 & 0.81 & 1.11 & 1.27 & 1.34 \\
\hline L-T5-M2-W-L500 & 55.5 & 0.95 & 0.97 & 1.02 & 1.32 & 0.46 & 0.89 & 1.42 & 1.20 \\
\hline L-T5-M2-W-L1200 & 55.5 & 0.57 & 0.57 & 1.10 & 1.51 & 0.50 & 0.82 & 1.00 & 0.86 \\
\hline L-T5-M2-W-L2000 & 55.4 & 0.61 & 0.61 & 1.38 & 1.83 & 0.55 & 0.82 & 1.28 & 1.11 \\
\hline L-T5-M2-W-L2700 & 49.3 & 0.66 & 0.66 & 1.70 & 2.09 & 0.57 & 0.82 & 1.64 & 1.42 \\
\hline L-T5-M2-W-L3500 & 45.2 & 0.72 & 0.72 & 2.19 & 2.65 & 0.72 & 0.98 & 1.46 & 1.27 \\
\hline L-T5-M3-W-L500 & 35.5 & 1.27 & 1.27 & 1.47 & 2.12 & 0.60 & 1.24 & 1.55 & 1.32 \\
\hline L-T5-M3-W-L1200 & 35.4 & 1.21 & 1.21 & 1.57 & 2.46 & 0.74 & 1.31 & 1.20 & 1.06 \\
\hline L-T5-M3-W-L2000 & 33.2 & 1.60 & 1.60 & 1.68 & 2.86 & 0.71 & 1.14 & 1.46 & 1.28 \\
\hline L-T5-M3-W-L2700 & 31.0 & 1.83 & 1.83 & 2.06 & 3.47 & 0.77 & 1.18 & 1.60 & 1.41 \\
\hline L-T5-M3-W-L3500 & 28.1 & 1.97 & 1.97 & 2.61 & 4.40 & 0.81 & 1.18 & 1.61 & 1.43 \\
\hline L-T5-M4-W-L500 & 38.3 & 1.51 & 1.51 & 1.56 & 2.30 & 0.68 & 1.40 & 1.67 & 1.36 \\
\hline L-T5-M4-W-L1200 & 39.0 & 1.49 & 1.49 & 1.69 & 2.77 & 0.74 & 1.30 & 1.39 & 1.17 \\
\hline L-T5-M4-W-L2000 & 34.5 & 1.86 & 1.86 & 1.63 & 3.09 & 0.78 & 1.26 & 1.56 & 1.31 \\
\hline L-T5-M4-W-L2700 & 32.0 & 2.10 & 2.10 & 1.68 & 3.78 & 0.79 & 1.21 & 1.66 & 1.40 \\
\hline L-T5-M4-W-L3500 & 28.2 & 2.21 & 2.21 & 1.90 & 4.67 & 0.87 & 1.27 & 1.71 & 1.45 \\
\hline L-T5-M5-W-L500 & 44.3 & 1.71 & 1.71 & 1.16 & 1.55 & 0.75 & 1.55 & 1.66 & 1.40 \\
\hline L-T5-M5-W-L1200 & 43.4 & 1.19 & 1.19 & 1.21 & 1.77 & 0.89 & 1.58 & 1.64 & 1.38 \\
\hline L-T5-M5-W-L2000 & 39.2 & 1.42 & 1.42 & 1.21 & 1.95 & 1.00 & 1.62 & 1.80 & 1.51 \\
\hline L-T5-M5-W-L2700 & 36.3 & 1.61 & 1.61 & 1.27 & 2.30 & 1.02 & 1.56 & 1.78 & 1.50 \\
\hline L-T5-M5-W-L3500 & 32.5 & 1.71 & 1.71 & 1.37 & 2.82 & 0.95 & 1.38 & 1.72 & 1.45 \\
\hline Mean, $P_{m}$ & & 1.24 & 1.25 & 1.66 & 2.35 & 0.74 & 1.20 & 1.46 & 1.29 \\
\hline $\mathrm{COV}, V_{p}$ & & 0.467 & 0.452 & 0.378 & 0.416 & 0.195 & 0.193 & 0.176 & 0.137 \\
\hline Resistance factor, $\phi$ & & 0.85 & 0.85 & 0.91 & 0.83 & 0.85 & 0.85 & 0.85 & 0.85 \\
\hline Reliability index, $\beta$ & & 1.83 & 1.90 & 2.54 & 3.40 & 1.22 & 2.84 & 3.72 & 3.61 \\
\hline
\end{tabular}


Table 8. Comparison between numerical results and design predictions for series L-T6

\begin{tabular}{|c|c|c|c|c|c|c|c|c|c|}
\hline \multirow{3}{*}{ Specimen } & \multirow{3}{*}{$\begin{array}{c}\text { FEA } \\
P_{F E}(k N)\end{array}$} & \multicolumn{8}{|c|}{ Comparison } \\
\hline & & $P_{F E}$ & $P_{F E}$ & $P_{F E}$ & $P_{F E}$ & $P_{F E}$ & $P_{F E}$ & $P_{F E}$ & $P_{F E}$ \\
\hline & & $\overline{P_{A A}}$ & $\overline{P_{A S / N A S}}$ & $\overline{P_{E C 9}}$ & $\overline{P_{C N}}$ & $\overline{P_{D S M}}$ & $\overline{P_{D S M-W}}$ & $\overline{P_{C S M-W 1}}$ & $\overline{P_{C S M-W 2}}$ \\
\hline L-T6-M1-W-L500 & 53.9 & 0.83 & 0.91 & 0.99 & 1.07 & 0.60 & 1.16 & 1.04 & 1.23 \\
\hline L-T6-M1-W-L1200 & 44.0 & 0.41 & 0.46 & 1.37 & 0.95 & 0.74 & 1.22 & 0.73 & 0.86 \\
\hline L-T6-M1-W-L2000 & 35.3 & 0.41 & 0.47 & 2.19 & 0.94 & 0.71 & 1.07 & 1.04 & 1.23 \\
\hline L-T6-M1-W-L2700 & 25.4 & 0.36 & 0.42 & 2.36 & 0.94 & 0.71 & 1.01 & 1.21 & 1.43 \\
\hline L-T6-M1-W-L3500 & 19.3 & 0.68 & 0.76 & 2.50 & 2.21 & 0.74 & 1.01 & 1.09 & 1.28 \\
\hline L-T6-M2-W-L500 & 60.4 & 0.79 & 0.79 & 0.97 & 1.09 & 0.41 & 0.79 & 1.35 & 1.18 \\
\hline L-T6-M2-W-L1200 & 60.5 & 0.57 & 0.57 & 1.08 & 1.21 & 0.45 & 0.74 & 1.31 & 1.15 \\
\hline L-T6-M2-W-L2000 & 62.8 & 0.83 & 0.83 & 1.66 & 1.54 & 0.53 & 0.80 & 1.07 & 0.93 \\
\hline L-T6-M2-W-L2700 & 53.3 & 0.86 & 0.86 & 2.07 & 1.83 & 0.55 & 0.79 & 1.15 & 1.00 \\
\hline L-T6-M2-W-L3500 & 48.0 & 0.92 & 0.92 & 2.69 & 2.48 & 0.74 & 1.01 & 1.51 & 1.32 \\
\hline L-T6-M3-W-L500 & 38.7 & 1.26 & 1.26 & 1.58 & 1.90 & 0.54 & 1.11 & 1.56 & 1.46 \\
\hline L-T6-M3-W-L1200 & 38.4 & 1.45 & 1.45 & 1.65 & 2.11 & 0.69 & 1.22 & 1.25 & 1.17 \\
\hline L-T6-M3-W-L2000 & 35.5 & 1.88 & 1.88 & 1.95 & 2.47 & 0.65 & 1.05 & 1.12 & 1.05 \\
\hline L-T6-M3-W-L2700 & 33.1 & 2.15 & 2.15 & 2.50 & 3.27 & 0.70 & 1.08 & 1.68 & 1.57 \\
\hline L-T6-M3-W-L3500 & 27.4 & 2.11 & 2.11 & 2.96 & 4.09 & 0.78 & 1.14 & 1.36 & 1.27 \\
\hline L-T6-M4-W-L500 & 40.5 & 1.43 & 1.43 & 1.63 & 1.98 & 0.59 & 1.22 & 1.45 & 1.29 \\
\hline L-T6-M4-W-L1200 & 41.3 & 1.76 & 1.76 & 1.73 & 2.31 & 0.67 & 1.18 & 1.53 & 1.36 \\
\hline L-T6-M4-W-L2000 & 36.5 & 2.18 & 2.18 & 1.70 & 2.63 & 0.71 & 1.15 & 1.22 & 1.08 \\
\hline L-T6-M4-W-L2700 & 33.2 & 2.43 & 2.43 & 1.90 & 3.46 & 0.76 & 1.16 & 1.37 & 1.21 \\
\hline L-T6-M4-W-L3500 & 27.8 & 2.41 & 2.41 & 2.14 & 4.40 & 0.86 & 1.25 & 1.47 & 1.30 \\
\hline L-T6-M5-W-L500 & 47.1 & 1.55 & 1.55 & 1.08 & 1.20 & 0.68 & 1.40 & 1.71 & 1.26 \\
\hline L-T6-M5-W-L1200 & 46.6 & 1.25 & 1.25 & 1.13 & 1.32 & 1.05 & 1.86 & 1.69 & 1.25 \\
\hline L-T6-M5-W-L2000 & 41.7 & 1.58 & 1.58 & 1.10 & 1.46 & 0.93 & 1.49 & 1.59 & 1.18 \\
\hline L-T6-M5-W-L2700 & 38.5 & 1.78 & 1.78 & 1.25 & 1.86 & 0.94 & 1.44 & 1.69 & 1.25 \\
\hline L-T6-M5-W-L3500 & 33.8 & 1.86 & 1.86 & 1.48 & 2.44 & 0.92 & 1.34 & 1.95 & 1.45 \\
\hline Mean, $P_{m}$ & & 1.35 & 1.36 & 1.75 & 2.05 & 0.71 & 1.15 & 1.36 & 1.23 \\
\hline $\mathrm{COV}, V_{p}$ & & 0.485 & 0.468 & 0.326 & 0.472 & 0.219 & 0.215 & 0.205 & 0.133 \\
\hline Resistance factor, $\phi$ & & 0.85 & 0.85 & 0.91 & 0.83 & 0.85 & 0.85 & 0.85 & 0.85 \\
\hline Reliability index, $\beta$ & & 1.93 & 2.01 & 2.96 & 2.81 & 1.02 & 2.55 & 3.27 & 3.47 \\
\hline
\end{tabular}

